\title{
La acción humanitaria y las personas con discapacidad
}

\section{Humanitarian action and persons with disabilities}

\section{Resumen}

El presente trabajo se propone realizar un análisis de las principales cuestiones relativas a la toma en consideración efectiva de la discapacidad en el ámbito de la acción humanitaria, tanto desde un punto de vista sincrónico (marcos conceptuales y normativos existentes, consensos alcanzados, principales necesidades y respuestas a las mismas) como diacrónico (principios en transformación en los ámbitos humanitarios y de la discapacidad, perspectiva histórica sobre los principales hitos internacionales en la materia, retos de futuro). Para ello, se llevará a cabo un repaso de los principales acuerdos multilaterales y documentos estratégicos, así como de la literatura más destacada sobre el tema, poniendo de relieve el papel destacado de la Convención de Naciones Unidas sobre los Derechos de las Personas con Discapacidad y la Carta sobre la Inclusión de Personas con Discapacidad en la Acción Humanitaria, y señalando igualmente las carencias aún existentes para su plena implementación.

\section{Palabras clave}

Discapacidad, acción humanitaria, inclusión, derechos humanos, conflictos, desastres naturales.

\begin{abstract}
This paper aims to carry out an analysis of the main issues regarding the inclusion of disability in the field of humanitarian action, both from a synchronic and a diachronic point of view (principles in transformation in the humanitarian and disability fields, historical perspective on the main international milestones in the matter, existing conceptual and normative frameworks, consensus reached regarding main needs and the responses to them, subsisting challenges...). To this end, a review of the main multilateral agreements and strategic documents will be carried out, as well as relevant literature on the subject, highlighting the prominent role of the United Nations Convention on the Rights of Persons with Disabilities and the Charter on the Inclusion of Persons with Disabilities in Humanitarian Action, while also pointing out the gaps that still exist for their full implementation.
\end{abstract}

\section{Keywords}

Disability, humanitarian action, inclusion, human rights, conflicts, natural disasters.

\author{
Sergio Colina Martín \\ <sergiocolinamartin@gmail.com> \\ Escuela Diplomática. España
}

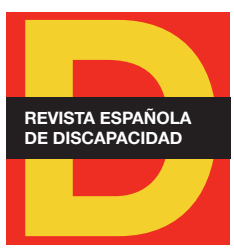

Para citar:

Colina, S. (2021). La acción

humanitaria y las personas con discapacidad. Revista Española de Discapacidad, 9(1), pp. 7-31.

Doi: <https://doi.org/10.5569/23405104.09.01.01>

Fecha de recepción: 12-02-2021

Fecha de aceptación: 28-04-2021 


\section{Introducción}

La toma en consideración de las personas con discapacidad en la acción humanitaria es un tema complejo, entre otros motivos porque se encuentra en la intersección entre distintas esferas de teoría y praxis en constante evolución, tanto desde el punto de vista conceptual como operativo. Los principios mismos de la acción humanitaria - humanidad, imparcialidad, neutralidad, independencia ${ }^{1}$ (OCHA, 2019a) - siguen sometidos en mayor o menor grado a discusión (Consejo Noruego para los Refugiados - Handicap International, 2016), bien respecto a la forma de entenderlos y concretarlos, bien directamente respecto a la validez de alguno de ellos. Todo ello en el marco de un debate inconcluso entre (por simplificar) un humanitarismo clásico, basado en el llamado paradigma "dunantista", y un "nuevo humanitarismo" que incluiría distintos contramodelos, entre ellos el paradigma de la resiliencia² (Hilhorst, 2018; Fox, 2001). Esto afecta de manera importante, por ejemplo, a la relación de lo humanitario con la protección de los derechos humanos y la posibilidad o pertinencia de una acción humanitaria basada en derechos (Gordon y Donini, 2016).

También los paradigmas para la comprensión de la discapacidad, desde las distintas disciplinas, han experimentado importantes cambios en las últimas décadas. A grandes rasgos, se ha hablado de un tránsito desde un enfoque médico, basado en la idea de enfermedad (y la patologización) hacia un enfoque de derechos (Hernández Ríos, 2015). Más concretamente, se ha apuntado a una evolución desde un modelo tradicional (animismo, nociones de castigo divino o presencia sobrenatural) a un paradigma de la autonomía personal pasando por el estadio intermedio del paradigma de la rehabilitación (Puig de la Bellacasa, 1990); es decir, desde un sistema basado en la prescindencia, que "relegaba a las personas con discapacidad a una situación de exclusión y segregación", a otro modelo social que, basado en "la autodeterminación, tiene como meta compartida principal, por todos los agentes sociales, la inclusión y la igualdad de derechos" (López Bastías, 2019). Algunos esquemas más refinados añaden al modelo de prescindencia, al médico-rehabilitador (o asistencial) y al social, el paradigma (más reciente) de la diversidad y un "enfoque de capacidades y funcionamientos" basado en las aportaciones de Amartya Sen y su énfasis en el bienestar, la calidad de vida y la libertad de las personas (Toboso y Arnau, 2008). Sea como fuere, muchos autores señalan que en realidad estos modelos o formas de entender la discapacidad no han sido mutuamente excluyentes, sino que han convivido a lo largo del tiempo (Egea y Sarabia, 2004), dando lugar en la actualidad a la coexistencia de enfoques multiparadigmáticos y variados modelos conceptuales (Mercer, 1992) que permanecen en evolución.

Más allá de los debates teóricos, todo ello tiene indudables repercusiones en la comprensión de los contextos sobre los que debe actuar la comunidad humanitaria en general -y por tanto también sobre cómo debería hacerlo-, incluido desde el punto de vista de la toma en consideración de la realidad de las personas con discapacidad según el contexto. Por poner solo un ejemplo: la discapacidad a menudo se considera un resultado de salud experimentado de manera desproporcionada por determinados grupos minoritarios; sin embargo, también es posible concebir a las personas con discapacidades como un grupo minoritario que experimenta disparidades respecto al ámbito de la salud, entre otros (McDonald y Raymaker, 2013). El diseño de la respuesta que se considere más adecuada a las necesidades en materia de salud de las per-

1. Cf. resoluciones de la Asamblea General de las Naciones Unidas 46/182 (1991) y 58/114 (2003).

2. La resiliencia, en el contexto humanitario, puede entenderse como "la capacidad de un sistema, comunidad o sociedad expuestos a una amenaza para resistir, absorber, adaptarse y recuperarse de sus efectos de manera oportuna y eficaz, lo que incluye la preservación y la restauración de sus estructuras y funciones básicas (UNISDR, 2009, p. 28). 
sonas y colectivos más vulnerables en un determinado contexto humanitario dependerá, en parte, de cuál de estos enfoques se adopte. Por todo ello, resulta relevante tratar de acotar algunos conceptos básicos, al menos de forma provisional y parcial, para a continuación poder analizar los principales marcos normativos, operativos y deontológicos que actualmente tratan de abordar la cuestión de la situación de las personas con discapacidad en el ámbito humanitario.

En primer lugar, es posible entender la acción humanitaria como el "conjunto diverso de acciones de ayuda a las víctimas de desastres (desencadenados por catástrofes naturales o por conflictos armados), orientadas a aliviar su sufrimiento, garantizar su subsistencia, proteger sus derechos fundamentales y defender su dignidad, así como, a veces, a frenar el proceso de desestructuración socioeconómica de la comunidad y prepararlos ante desastres naturales"; acciones que pueden ser llevadas a cabo por actores nacionales o internacionales - en este segundo caso, con carácter subsidiario respecto a la responsabilidad del Estado de asistencia a su propia población- (Pérez de Armiño, 2008). A su vez, dichos desastres pueden ser entendidos como "una seria interrupción en el funcionamiento de una comunidad o sociedad que ocasiona una gran cantidad de muertes al igual que pérdidas e impactos materiales, económicos y ambientales que exceden la capacidad de la comunidad o la sociedad afectada para hacer frente a la situación mediante el uso de sus propios recursos" (UNISDR, 2009, pp. 13-14).

Cabe señalar que, hasta el siglo XIX, las intervenciones humanitarias no contaban con normas ni marcos estructurados y respondían más bien a creencias religiosas o a solidaridades concretas de tipo político, centrándose habitualmente en proporcionar ayuda de manera puntual con ocasión de hambrunas, sequías y desastres naturales, y no tanto en contextos bélicos ${ }^{3}$ (Townes, 2018). Actualmente, como se desprende de la definición propuesta, la actuación humanitaria se enfoca tanto hacia desastres naturales como hacia distintos contextos de violencia armada. El derecho internacional humanitario (DIH) trata de regular estos últimos contextos, tanto en lo relativo a los conflictos de naturaleza internacional como no internacional (Vité, 2009). El ámbito de actuación humanitaria incluye pues la respuesta a los efectos de las guerras entre estados (Weiss, 1998) y los conflictos intraestatales (Meininghaus, 2016), aunque también situaciones que no responden a las definiciones tradicionales de conflicto, pero cuyo nivel de crudeza tiene amplios impactos sobre las poblaciones y puede terminar generando importantes necesidades humanitarias (Briscoe, 2013).

En un sentido amplio, la acción humanitaria puede incluir, además de la cobertura de necesidades en situaciones de conflicto o desastres naturales, el apoyo a poblaciones desplazadas como consecuencia de crisis agudas y prolongadas, así como capacitación en materia de reducción de riesgos y preparación ante desastres, actuaciones de recuperación temprana y de apoyo a los medios de vida de las personas afectadas, etc. (Davey et al., 2013: 1). Cabe subrayar que, aunque en el ámbito especializado no es indiferente el uso de términos como "socorro", "emergencia", "ayuda humanitaria" o "acción humanitaria"5 (Celorio y López de Munain, 2007), a los efectos del presente artículo se entenderán dichos conceptos de una forma general y aproximadamente homogénea.

3. Existe consenso en determinar que el ámbito de los conflictos armados como escenario de la actuación humanitaria cobró protagonismo a raíz de la batalla de Solferino (1859) y la consiguiente acción de Henri Dunant (McFarland, 2017).

4. Una crisis o emergencia puede definirse como una "condición amenazante que requiere de la toma de acciones urgentes", de tal modo que una actuación eficaz frente a una emergencia puede llegar a evitar que dicho evento escale hasta el punto de convertirse en un desastre, aunque en ocasiones la expresión "gestión de emergencias" también se utiliza como equivalente a "gestión de desastres" (UNISDR, 2009).

5. Algunos autores consideran, por ejemplo, que el concepto de "acción humanitaria" se confunde indebidamente con el de "ayuda humanitaria" en la medida en que esta última "está dirigida a las víctimas prolongadas de un desastre natural o un conflicto armado, como los desplazados o refugiados, una vez ya han recibido la primera ayuda de emergencia", mientras que la acción humanitaria tendría un "carácter más amplio, ya que también busca prevenir, proteger la dignidad y los derechos de la población vulnerable, proporcionar bienes y servicios básicos para garantizar su subsistencia" (El Orden Mundial, 2020). 
En segundo lugar, surge la cuestión de la noción de discapacidad, ya que, como han subrayado diversos autores, a menudo se plantea la necesidad de adoptar marcos conceptuales similares y un lenguaje común internacional para evitar que la coexistencia de definiciones diferentes pueda generar confusión (Jette, 2009) -en el caso que nos ocupa, entre los actores humanitarios que se plantean abordar de forma armónica las necesidades de las personas con discapacidad-. Tal y como recuerdan Abellán e Hidalgo (2011), la propia Organización Mundial de la Salud (OMS) ha ido modificado a lo largo de las últimas décadas los términos y conceptos empleados en sus clasificaciones internacionales de discapacidad (OMS, 1980; OMS, 2001). La OMS "no fue ajena al problema terminológico", e incluso durante los años siguientes a la aprobación de la Clasificación Internacional del Funcionamiento, de la Discapacidad y de la Salud "tuvo que llegar a un acuerdo sobre la utilización de los términos más importantes con una serie de organizaciones internacionales", pese a lo cual, en muchos casos, "no se ha podido evitar el uso como sinónimos, no sólo en la lengua común sino, incluso, en mucha de la literatura especializada, de términos y conceptos de naturaleza diferente" (Egea y Sarabia, 2003).

Actualmente, la OMS adopta una noción de discapacidad como término general que abarca impedimentos, limitaciones de la actividad y restricciones de la participación de las personas. Ello significa tomar en cuenta los problemas que afectan a la estructura y función corporales, las dificultades encontradas para poder ejecutar acciones o tareas, y los problemas para participar en situaciones vitales. Por consiguiente, la discapacidad es un fenómeno complejo que refleja una interacción entre las características del organismo humano y las características de la sociedad en la que vive, y las intervenciones para superar las desventajas asociadas a ella son múltiples, sistémicas y varían según el contexto (OMS, 2011). Ello incluye también, lógicamente, a las actuaciones de naturaleza humanitaria.

Por su parte, la Convención de Naciones Unidas sobre los Derechos de las Personas con Discapacidad (CDPD), que analizaremos con detenimiento más adelante, considera que esta noción incluye a aquellas personas "que tienen deficiencias físicas, mentales, intelectuales o sensoriales a largo plazo que, al interactuar con diversas barreras, puedan impedir su participación plena y efectiva en la sociedad, en igualdad de condiciones con las demás" (ONU, 2006). Es importante destacar que la Convención no contiene una definición cerrada de quiénes son las personas con discapacidad. La discapacidad no es un concepto rígido ni inmutable, sino un concepto que evoluciona y que además puede adaptarse al entorno imperante en una determinada sociedad; discapacidad no es un problema médico, sino "una interacción entre una deficiencia y su entorno" (para la Convención, "las personas pasan a tener una discapacidad cuando colisionan con un entorno desfavorable o inaccesible"); la Convención no se limita a personas concretas, sino que incluye a las personas con discapacidades físicas, mentales, intelectuales y sensoriales a largo plazo y hace igualmente extensiva su aplicación a las personas con discapacidad a corto plazo o las personas a las que se considere parte de tales grupos; en definitiva, lo que propugna la Convención es que deben clasificarse las barreras existentes (en tanto que factores constitutivos de la discapacidad que determinan los problemas a los que deben enfrentarse las personas con discapacidad) y no a los seres humanos (OACNUDH, 2014, pp. 19-20). Este enfoque subraya que las barreras reales para la participación plena no residen en el individuo, sino más bien en el entorno social, actitudinal, arquitectónico, médico, económico y político (National Council on Disability, 2002).

Una vez analizados brevemente los conceptos de acción humanitaria y de discapacidad, cabe ya formularse la siguiente pregunta central: ¿por qué se plantea como una cuestión acuciante la toma en consideración efectiva y sistemática de las personas con discapacidad en la acción humanitaria? Para abordarla hay que 
tener en cuenta, al menos, dos dimensiones fundamentales: la interacción de facto entre las discapacidades y los distintos contextos humanitarios, por un lado, y la inclusión efectiva (o falta de ella) de estas consideraciones en la actuación de los actores humanitarios, por otro. Por último, no debe olvidarse que a menudo las emergencias terminan creando nuevas generaciones de personas que experimentan discapacidades debido a lesiones, atención médica y quirúrgica deficiente, el abandono y ruptura de las estructuras de apoyo y atención sanitaria preventiva, los problemas psicológicos y de salud mental inducidos por el trauma de la emergencia en cuestión y sus efectos, etc., y que en situaciones de disrupción de los servicios médicos, las lesiones no tratadas o tratadas de forma inadecuada pueden provocar, y a menudo provocan, muertes innecesarias y deterioros graves y duraderos en la salud y las condiciones físicas y psíquicas de las personas (OMS, 2013, p. 10).

\section{Personas con discapacidad y contextos humanitarios de conflicto o desastre natural}

De manera general, los estudios sobre la situación de las personas con discapacidad en contextos humanitarios concluyen que hay evidencia suficiente de que estas se ven desproporcionadamente afectadas por los mismos, pero aún hay pocos datos, en cambio, sobre las dinámicas que conducen a ello (Smith et al., 2012, p. 2). La Encuesta Mundial de Salud indica que la prevalencia de la discapacidad es mayor en los países de ingresos bajos y que las personas en el quintil más pobre, las mujeres y las personas ancianas también presentan una mayor prevalencia de la discapacidad (OMS, 2011). Sin embargo, es necesario subrayar que las personas con discapacidad se ven desproporcionadamente impactadas principalmente como consecuencia de las desventajas sociales existentes, la pobreza y la exclusión estructural a la que a menudo se ven sometidas, más que por cualquier tipo de vulnerabilidad inherente (Hemingway y Priestley, 2006, p. 64) o per se.

Si bien la discapacidad se correlaciona de forma habitual con la desventaja debido a la existencia de las mencionadas barreras, no todas las personas con discapacidad están igualmente en una situación de desventaja en un determinado contexto: las personas con discapacidades más graves a menudo experimentan mayores desventajas, y en algunos contextos, las mujeres con discapacidad, los niños y niñas, las personas mayores y las personas con problemas de salud mental y deficiencias intelectuales experimentan más discriminación y exclusión que otras personas con discapacidad (OMS, 2013, p. 9). La CDPD, en su artículo 11, dedicado a las obligaciones de los Estados parte en materia de protección y seguridad de las personas con discapacidad en situaciones de conflicto armado, emergencia humanitaria y desastres naturales, se abstuvo precisamente de usar expresiones referidas a la mayor vulnerabilidad de las personas con discapacidad que pudieran reforzar el estigma al que a menudo deben enfrentarse (OACNUDH, 2015). La Convención, en cambio, pone de relieve el hecho de que las personas con discapacidades pueden tener un mayor riesgo de sufrir daños físicos y mentales debido a la falta de una respuesta humanitaria inclusiva, que tenga debidamente en cuenta la discapacidad y por tanto agrave la discriminación y la exclusión preexistentes (Handicap International/CBM International/IDA, 2020).

En contextos humanitarios, las personas con discapacidad tienen más probabilidades de enfrentar barreras y obstáculos en el entorno físico, el transporte, la información y las comunicaciones y las instalaciones o 
servicios humanitarios (Sphere Association, 2018, p. 14). Las personas con discapacidades visuales, auditivas e intelectuales y las personas con condiciones de salud mental graves, así como aquellas personas con discapacidad que en determinados contextos son socialmente excluidas de forma más intensa, o que se encuentran internas en instituciones, suelen correr un mayor riesgo de no estar preparadas para eventos que conducen a emergencias, aumentando las posibilidades de que no sepan o no entiendan lo que está sucediendo (OMS, 2013). En todo caso, procede analizar de manera más detallada qué tipo de barreras son aquellas que de manera general prevalecen en contextos de conflicto armado, por un lado, y de desastre natural, por otro.

Como hemos señalado, las personas con discapacidad a menudo tienen especiales dificultades para acceder a servicios básicos como la atención médica (Hashemi et al., 2020) o la educación (UNESCO, 2020), o para disfrutar de manera efectiva de los derechos humanos al agua y el saneamiento (Banks et al., 2019; Groce, 2011b). Estas dificultades preexistentes se ven exacerbadas en situaciones de conflicto armado, tanto por la disrupción general de los servicios sanitarios y de atención social habituales como por las barreras añadidas, tanto físicas como de acceso a la información o a los servicios aun disponibles, muchas veces incrementadas por la necesidad de huir de sus hogares en busca de seguridad. Se puede suponer que las personas con discapacidad experimentarán pobreza en contextos de conflicto, ya que el conflicto exacerba las condiciones previas de pobreza, discriminación y exclusión social, aunque se necesita más investigación sobre los vínculos causales entre discapacidad y pobreza en países afectados por conflictos (Kett, 2010); y aunque la discapacidad y la pobreza y la relación entre ambas son cuestiones complejas y fenómenos dinámicos que resulta difícil abordar mediante un único modelo teórico cerrado (Eide e Ingstad, 2011, p. 225). En cualquier caso, en situaciones de conflicto armado, las personas con discapacidad corren un mayor riesgo de muerte y lesiones como resultado de problemas de movilidad y comunicación, que pueden dificultar la mencionada huida de la violencia (Rohwerder, 2013, p. 774-775).

En cuanto a los contextos de catástrofe natural, las estadísticas disponibles en materia de gestión de emergencias indican que las personas con discapacidad mueren en porcentajes mucho más altos (Mitchell y Karr, 2014, p. 1). La discriminación preexiste a la ocurrencia de los desastres, pero se agrava durante una emergencia; estas discriminaciones suelen ser invisibles en gran parte debido a la falta de datos oficiales, invisibilidad que se agrava cuando los actores humanitarios llevan a cabo actuaciones de emergencia sin evaluaciones previas que incluyan un análisis acerca de las personas vulnerabilizadas (incluidas, en muchos casos, las personas con discapacidad) y sus necesidades (IFRC, 2007, p. 13).

El Marco de Sendai para la Reducción del Riesgo de Desastres ${ }^{6}$ incorporó consideraciones relevantes relativas a la discapacidad, y si bien reconoce la función de liderazgo y coordinación que deben desempeñar los gobiernos, insiste en que estos deben interactuar con los actores pertinentes, entre ellos las personas con discapacidad, en el diseño y aplicación de políticas, planes y normas, recordando que la reducción del riesgo de desastres requiere la implicación de toda la sociedad, y por tanto debe garantizar una participación inclusiva, accesible y no discriminatoria que preste especial atención a las personas afectadas desproporcionadamente por los desastres. El Marco reitera la necesidad de integrar las perspectivas de género, edad y discapacidad y de empoderar a las personas con discapacidad para que encabecen y promuevan públicamente enfoques basados en el acceso universal en materia de respuesta, recuperación, rehabilita-

6. Adoptado en el marco de la Tercera Conferencia Mundial de las Naciones Unidas sobre la Reducción del Riesgo de Desastre. La Asamblea General de las Naciones Unidas hizo suya la Declaración de Sendai y el Marco de Sendai para la Reducción del Riesgo de Desastres $2015-2030$ mediante resolución aprobada el 3 de junio de 2015 (A/RES/69/283). 
ción y reconstrucción, así como en la disponibilidad de información sobre los riesgos fácilmente accesible, actualizada, comprensible para todas las personas (ONU, 2015).

El Comité sobre los Derechos de las Personas con Discapacidad ${ }^{7}$ ha elaborado varias normas en sus observaciones finales con arreglo al artículo 11 de la CDPD, al que ya nos hemos referido, y ha señalado que los Estados están obligados a adoptar o reformar los planes y protocolos nacionales de respuesta a situaciones de emergencia, de modo que sean inclusivos y accesibles para las personas con discapacidad en su diseño y aplicación; que estas reformas deberían incluir a las personas con discapacidad en los planes de evacuación y garantizar las asignaciones presupuestarias necesarias; y, en definitiva, que los Estados partes están obligados a integrar las cuestiones relativas a la discapacidad en sus políticas sobre migración y refugiados y en todos los canales de ayuda humanitaria. El Comité ha exhortado a que se garantice y priorice la seguridad de todos los niños y niñas con discapacidad en las zonas afectadas por el conflicto, especialmente de aquellos niños que viven en instituciones, ha instado al registro sistemático de las personas con discapacidad internamente desplazadas, y ha pedido que se vigile su situación, así como la de las que se encuentren en campamentos de refugiados, a fin de asegurar un nivel de vida adecuado (OACNUDH, 2015) ${ }^{8}$.

Todo lo anteriormente expuesto permite establecer una primera aproximación a las obligaciones internacionales concretas de los Estados parte de la CDPD en materia de protección y seguridad de las personas con discapacidad en situaciones de emergencia humanitaria. Pero una comprensión completa de las interacciones entre estas y la discapacidad es necesario prestar atención también a la manera en que las agencias y organizaciones humanitarias abordan estas cuestiones, tanto para garantizar el cumplimiento del principio básico de "do no harm" como para asegurar que se respeta el principio de imparcialidad, que determina que la acción humanitaria debe llevarse a cabo en función de la necesidad de las personas, dando prioridad a los casos más urgentes (Unión Europea, 2008). Puesto que todas las personas tienen la misma dignidad y los mismos derechos, y la ayuda humanitaria se proporciona de acuerdo con el principio de humanidad, cada individuo debe recibir asistencia de acuerdo a sus necesidades (Quack, 2018, p. 11).

7. Aunque otros comités (como el Comité de Derechos Económicos, Sociales y Culturales o el Comité de los Derechos del Niño) han formulado observaciones generales relevantes respecto a las personas con discapacidad, el Comité sobre los Derechos de las Personas con Discapacidad ha desarrollado, lógicamente, un papel fundamental en este ámbito (Salmón, 2014).

8. Así, por ejemplo, el Comité instó a Ucrania a adoptar "todas las medidas necesarias, también a nivel local, para facilitar la protección, incluida la evacuación, de las personas con discapacidad que actualmente siguen en las zonas de conflicto en el país" y velar por que "sus mecanismos de respuesta en caso de emergencia y sus planes de evacuación incluyan a todas las personas con discapacidad, y sean accesibles para estas" (CRPD/C/UKR/CO/1); recomendó a las islas Cook que llevasen a cabo una recopilación sistemática de datos desglosados que sirviera de fundamento para la elaboración de protocolos accesibles e inclusivos, especialmente para las personas sordas, y que garantizase las asignaciones presupuestarias necesarias, incluido el recurso a la financiación procedente de la cooperación internacional (CRPD/C/COK/CO/1); expresó preocupación ante Colombia por el hecho de que en el proceso de negociación de paz no se hubiera considerado prioritaria la inclusión de la perspectiva de la discapacidad en la rehabilitación y reinserción social de víctimas con discapacidad (CRPD/C/COL/CO/1); y solicitó a Kenia que aprobase un plan nacional para proteger a las personas con discapacidad en situaciones de riesgo y emergencias humanitarias, que garantizase la inclusión y la accesibilidad universal en todas las fases y niveles de las políticas de reducción del riesgo de desastres y su aplicación, y que adoptase medidas para vigilar la situación de las personas con discapacidad en los campamentos de refugiados y los desplazados internos con discapacidad (CRPD/C/KEN/CO/1).

9. Este principio, que proviene del ámbito de la deontología médica, requiere que las organizaciones humanitarias se esfuercen por minimizar el daño que pueden causar inadvertidamente al brindar ayuda, así como también los daños que pueden ser causados por no brindar ayuda (PNUD, 2016). Esto puede concretarse, por ejemplo, en aumentar las tensiones en o con las comunidades de acogida, o, en el caso concreto que nos ocupa, en profundizar involuntariamente la discriminación y vulnerabilidad a las que ya se veían expuestas las personas con discapacidad. 


\section{Personas con discapacidad, principio de imparcialidad, derecho internacional humanitario y protección de las personas con discapacidad en situaciones de conflicto}

El principio de imparcialidad ha sido definido por algunos teóricos como un principio de acción a nivel micro, que requiere que toda la acción humanitaria se lleve a cabo únicamente sobre la base de, y en proporción, a la necesidad de las víctimas (Mačák, 2016). La formulación clásica del principio de imparcialidad se desgajaría más concretamente en tres componentes fundamentales: una cláusula de no discriminación (de tipo social, por así decirlo, o sea, en función de la pertenencia a un determinado grupo o colectivo), según la cual la ayuda se otorga independientemente de la raza, el credo, la nacionalidad, etc., de las personas destinatarias, sin distinción adversa de ningún tipo; una cláusula de proporcionalidad de la ayuda, según la cual las prioridades de la ayuda deben calcularse basándose únicamente en la necesidad; y una última cláusula de prohibición de cualquier juicio subjetivo acerca de la bondad o maldad, culpabilidad o inocencia de la persona en cuestión (Pictet, 1979; Mackintosh, 2000, p. 8).

Sin embargo, algunos autores han señalado que entre la primera y la segunda cláusula puede producirse en realidad una tensión, como entre dos polos que pueden llegar a demandar respuestas en ocasiones contrapuestas, en la medida en que la primera proporciona una lista no exhaustiva de discriminación infundada, mientras la segunda no da ningún ejemplo concreto de discriminación legítima, sino que simplemente establece una regla general, la de proporcionalidad -las prioridades de la ayuda se determinaran únicamente en función de la necesidad-, como presuponiendo la posibilidad de realizar un cálculo, una especie de objetivación matemática del sufrimiento humano. Frente a esto, surge la pregunta: ¿cómo distinguir entre formas de discriminación legítimas (exigidas por la mayor necesidad) y no legítimas (inadmisibles por la prohibición de distinción adversa)? (Glasman, 2020).

Desde un punto de vista teórico, se podría pensar que dicha tensión se puede resolver mediante un enfoque sobre la discapacidad que se centre en el análisis de las necesidades en un determinado contexto, y demanda que se adopten las medidas necesarias para que determinadas personas no se vean excluidas de la ayuda humanitaria por razón de su discapacidad, o por causa de determinados obstáculos o barreras no previstos o no tomados en consideración. Ciertos grupos específicos deben recibir una consideración especial en la evaluación de sus necesidades y la entrega de ayuda; estos deben incluir a los miembros sometidos a mayores riesgos por distintos motivos, que a menudo incluyen a la infancia, a las personas ancianas, a las personas refugiadas e internamente desplazadas, y muy a menudo también, a las personas con discapacidad (Pothiawala, 2015). Sin embargo, como se ha puesto de relieve al repasar el trabajo realizado por el Comité sobre los Derechos de las Personas con Discapacidad, estos grupos a menudo se ven excluidos del proceso de planificación de desastres antes, durante y después de una emergencia.

Desde un punto de vista normativo, el principio de no discriminación - que, como hemos visto constituye una de las patas del principio humanitario de imparcialidad - es asimismo considerado un principio fundamental del derecho internacional humanitario; de hecho, varias disposiciones de los Convenios de Ginebra y sus Protocolos adicionales establecen la importancia de la igualdad de trato de las personas sin distinción y del respeto de sus derechos fundamentales en todo caso (Haider, 2013). Más concretamente, el derecho internacional humanitario clásico establece claramente que esta prohibición de distinciones desfavorables se aplica a todas las personas que se encuentren en poder de una parte en conflicto o bajo el control territorial de una parte en conflicto. Y, aunque no se menciona explícitamente la "discapacidad" como motivo 
prohibido de distinción adversa, la noción genérica empleada para acotar el ámbito de esta prohibición - que incluye una cláusula de cierre relativa a "cualquier otro criterio similar" - se entiende que engloba la prohibición de distinción adversa basada en la discapacidad.

En este sentido, el Comité Internacional de la Cruz Roja $(\mathrm{CICR})^{10}$ considera que, bajo el derecho internacional humanitario, en situaciones de conflicto armado (tanto internacional como no internacional), las protecciones generales otorgadas a civiles y personas fuera de combate se aplican íntegramente a las personas con discapacidad, incluyendo lógicamente la obligación de tratar a las personas con discapacidad de forma humana en toda circunstancia - entendiendo que, en la práctica, esto significa también, por ejemplo, tener en cuenta sus particulares condiciones físicas y mentales, así como las barreras ambientales que afectan a las personas con discapacidades - y la obligación de permitir y facilitar el acceso de estas personas a la asistencia humanitaria. Además, considera que la obligación general de las partes en un conflicto armado de proteger a los civiles de ataques directos y ataques indiscriminados implica tener en cuenta las necesidades de las personas con discapacidades en aplicación del principio de precaución.

Por otra parte, y dado que el DIH solo prohíbe la distinción "adversa", se suele entender igualmente que las medidas diferenciadas o que prioricen la protección de las personas con discapacidad en base a sus necesidades específicas sí están permitidas, e incluso pueden ser requeridas. En realidad, se suele considerar que una de las reglas asentadas del derecho humanitario consuetudinario determina que las personas mayores, con discapacidad o enfermas afectadas por un conflicto armado tienen derecho a un especial respeto y protección (Henckaerts, 2005, p. 210). En el marco de las Convenciones de Ginebra, esto incluiría una dimensión "negativa" (no ser objetivo o víctimas de ataques) y también una "positiva" (recibir ayuda y protección), también (y de manera especial) en lo relativo a su eventual evacuación, detención o internamiento. El CICR sostiene que, de acuerdo con el DIH, las personas con discapacidad deben recibir en la medida de lo posible y con el mínimo retraso posible, la atención médica eventualmente requerida por su condición, sin distinción que se halle fundada en cualquier motivo distinto al criterio médico ${ }^{11}$.

Las Convenciones de Ginebra incluyen, además, diversas menciones concretas relativas a protección específica. Así, por ejemplo, el artículo 30 del Tercer Convenio de Ginebra, relativo al tratamiento de los prisioneros de guerra (1949), requiere que, en una situación de conflicto armado internacional, se pongan en marcha establecimientos específicos en los campos de prisioneros de guerra para el cuidado de las personas con discapacidad ${ }^{12}$ y su rehabilitación hasta el momento de su repatriación. Asimismo, el Convenio de Ginebra relativo a la protección de civiles en tiempo de guerra, o Cuarto Convenio de Ginebra, llama a las partes en conflicto a concluir acuerdos locales para la evacuación de personas con discapacidad de las áreas sitiadas o cercadas (artículo 17). También en situaciones de conflicto armado no internacional tienen derecho a especial respeto y protección de acuerdo con el derecho internacional humanitario consuetudinario.

10. https://bit.ly/3hL9DSK.

11. Ibid.

12. Cabe señalar, como curiosidad histórica, que el tenor literal se refiere de forma particularizada a las personas ciegas. 


\section{El Consejo de Seguridad de las Naciones Unidas y las personas con discapacidad en conflictos armados}

En algunas de sus resoluciones sobre la protección de civiles o la situación de la infancia en conflictos armados - por ejemplo, las resoluciones 1894 (2009) o la 2225 (2015) - , el Consejo de Seguridad ha subrayado la especial incidencia que los conflictos armados tienen en las personas con discapacidad. En otras resoluciones específicas sobre determinados contextos geográficos ${ }^{13}$ - por ejemplo, la 2217 (2015), sobre la situación en la República Centroafricana, o la 2459 (2019), sobre Sudán del Sur -, el Consejo ha expresado igualmente preocupación por la situación de abandono, violencia y la falta de acceso a los servicios básicos de las personas con discapacidad, y reiteró la necesidad de que las respuestas humanitarias incluyeran a las personas con discapacidad.

Sin embargo, no fue hasta junio de 2019 cuando el Consejo adoptó (por unanimidad) la primera resolución específica sobre la protección de personas con discapacidad en situaciones de conflicto: la resolución 2475. En ella, subraya la conveniencia de proporcionar una asistencia sostenible, oportuna, adecuada, inclusiva y accesible a los civiles con discapacidad afectados por conflictos armados, incluidos servicios para la reintegración y rehabilitación y apoyo psicosocial, a fin de atender de manera eficaz las necesidades específicas de esas personas, en particular las de las mujeres y la infancia con discapacidad; y alienta a los Estados Miembros a que adopten medidas adecuadas para que las personas con discapacidad tengan acceso en igualdad de condiciones a los servicios básicos prestados en situaciones de conflicto armado, en particular a los servicios de educación, atención de la salud y transporte y a los sistemas y las tecnologías de la información y las comunicaciones. Además, insta a que los Estados adopten todas las medidas apropiadas para eliminar la marginación por motivos de discapacidad en situaciones de conflicto armado, en particular de las personas que son objeto de formas múltiples e interrelacionadas de discriminación, y a que propicien la participación y la representación efectivas de las personas con discapacidad, incluidas sus organizaciones, en la acción humanitaria, la prevención y resolución de conflictos, la reconciliación, la reconstrucción y la consolidación de la paz.

\section{La Convención de Naciones Unidas sobre los Derechos de las Personas con Discapacidad}

La CDPD fue aprobada por la Asamblea General de la ONU en diciembre de $2006{ }^{14}$. Su Protocolo Facultativo reconoce la competencia del Comité sobre los Derechos de las Personas con Discapacidad para recibir y considerar las comunicaciones presentadas por personas o grupos de personas sujetos a la jurisdicción de los Estados parte que aleguen haber sido víctimas de una violación por ese Estado de cualquiera de las disposiciones de la Convención.

13. También puede resultar de interés el caso de Colombia en cuanto a la situación de las personas con discapacidad en relación con el conflicto armado en Colombia (Biel y Bolaños, 2018a, 2018b) y el escenario posconflicto, teniendo en cuenta que la implementación del Acuerdo de Paz es debatida periódicamente por el Consejo.

14. A/RES/61/106. 
Existe un amplio acuerdo en considerar que su adopción supuso un cambio relevante de paradigma (Mittler, 2015; Harpur, 2012), apuntalando a nivel internacional el tránsito desde un enfoque biologicista de la discapacidad (Cardona, 2007), que tendía a considerarla esencialmente desde el punto de vista de la atención médica o la beneficencia, hacia un enfoque basado en derechos y, por tanto, en el pleno reconocimiento de las personas con discapacidad como sujetos de derechos (Sanjosé, 2007) ${ }^{15}$. De hecho, la Convención es considerada como el primer instrumento internacional de derechos humanos jurídicamente vinculante que reconoce a las personas con discapacidad como sujetos de derechos humanos (Degener, 2017).

A grandes rasgos, la Convención define y aplica los principios de derechos humanos existentes a las personas con discapacidad, ofrece una base internacionalmente acordada para el desarrollo de normativas y políticas públicas en la materia por parte de los Estados, establece mecanismos nacionales e internacionales para una supervisión más efectiva de los derechos de las personas con discapacidad, y reconoce las circunstancias específicas de los niños y niñas y de las mujeres con discapacidad. Desde una perspectiva de derechos humanos, cabe destacar que la Convención incluye toda la gama de derechos económicos, sociales y culturales y los derechos civiles y políticos, y no separa en categorías distintas los derechos reconocidos, "con el objetivo de reforzar la indivisibilidad e interdependencia de todos los derechos humanos" (González Martín, 2008). La participación, la rendición de cuentas, la no discriminación y el empoderamiento son principios fundamentales del modelo basado en los derechos humanos de la discapacidad (OACNUDH, 2015). Pero la CDPD no se limita a adoptar el modelo clásico y constituye más que un modelo de igualdad y no discriminación, haciendo especial hincapié en la interacción entre las situaciones de falta de igualdad efectiva y discriminación, imponiendo a los Estados la adopción de medidas proactivas para modificar el statu quo, poniendo de relieve las necesidades especiales de protección de las personas con discapacidad y consagrando un reconocimiento del valor de la diversidad o la diferencia (Parra-Dussan, 2010).

Desde el punto de vista de la acción humanitaria, conviene subrayar, además, que la Convención cuenta con un artículo específico sobre ese ámbito, el artículo 11, en el que establece que los Estados Partes adoptarán, en virtud de las responsabilidades que les corresponden con arreglo al derecho internacional $-\mathrm{y}$ en concreto el derecho internacional humanitario y el derecho internacional de los derechos humanos - todas las medidas necesarias para garantizar la seguridad y la protección de las personas con discapacidad en situaciones de riesgo, incluidas situaciones de conflicto armado, emergencias humanitarias y desastres naturales.

En su resolución 28/4, el Consejo de Derechos Humanos solicitó a la Oficina del Alto Comisionado para los Derechos Humanos la elaboración de un estudio sobre el artículo 11 de la CDPD sobre situaciones de riesgo y emergencias humanitarias. Dicho informe puso de manifiesto que el derecho internacional humanitario había sido codificado "de acuerdo con la antigua concepción predominante de la discapacidad, a saber, el modelo médico de la discapacidad, que se centra exclusivamente en la deficiencia de la persona y refleja un enfoque paternalista con respecto a las personas con discapacidad", y estableció una serie de recomendaciones para garantizar que esos conceptos sean efectivamente sustituidos por un enfoque de la discapacidad basado en los derechos humanos, en el marco de la CDPD, lo cual exige "una nueva comprensión del derecho internacional humanitario, el derecho de los refugiados y los marcos de crisis aplicados a las personas con discapacidad" (OACNUDH, 2015).

15. Como se ha señalado anteriormente, esto responde a dinámicas generales existentes más allá del estricto ámbito de las Naciones Unidas: "la filosofía que está detrás de buena parte de los cambios normativos acaecidos en los últimos años en materia de discapacidad es la representada por el llamado modelo social de la discapacidad", que permitió abandonar planteamientos enfocados en la discapacidad como condición o rasgo ligado a "deficiencias" personales con nociones más amplias basadas en las estructuras y condicionamientos sociales existentes (de Asís, 2013, pp. 1-2). Sobre el modelo social y su conexión con un enfoque de derechos, cf. Palacios (2017) y Victoria (2013). 
En cuanto a las principales conclusiones del estudio en relación con la eficacia de la ayuda, la reducción de la exclusión de las personas con discapacidad y la gestión del riesgo, cabría destacar, entre otras, las siguientes: en primer lugar, que resulta imprescindible fomentar la colaboración entre las organizaciones locales, nacionales e internacionales que se dedican a cuestiones de discapacidad, garantizando un diálogo sustantivo y la difusión de buenas prácticas entre las organizaciones que representan a las personas con discapacidad, por un lado, y aquellas que se ocupan de cuestiones relacionadas con las situaciones de riesgo y las emergencias humanitarias, por otro. En segundo lugar, que es necesario trabajar en la detección sistemática de las personas con discapacidad, tanto aquellas que se puedan encontrar en situaciones de riesgo durante la crisis, como durante la fase de recuperación, con el fin de evitar que la falta de detección pueda conducir a su exclusión de la asistencia y los recursos en el marco de los programas, como el agua, el alojamiento o la vestimenta. En tercer lugar, que las estrategias de evacuación deben prestar una atención específica a las necesidades de las personas con discapacidad, en particular las que residen en instituciones. En los refugios de emergencia y provisionales las personas con discapacidad deben poder acceder al agua y al saneamiento Es fundamental proporcionar la información necesaria en formatos accesibles antes, durante y después de una situación de riesgo para garantizar la seguridad de las personas con discapacidad, especialmente las que tienen deficiencias auditivas, visuales e intelectuales.

De manera general, el informe insiste en la importancia de reforzar la recopilación, la gestión, el desglose y el análisis de información sobre las personas con discapacidad, y de generar más investigación cualitativa aplicada para lograr un mayor conocimiento de las cuestiones relativas a las personas con discapacidad en emergencias humanitarias, privilegiando la utilización de metodologías participativas que puedan describir mejor los requisitos, experiencias y prioridades de las personas con discapacidad, y promover la elaboración de políticas y prácticas inclusivas.

En cuanto a los escenarios poscrisis, señala que los Estados deben adoptar las medidas que permitan a las personas con discapacidad contar con el apoyo necesario para reconstruir su vida y medios de subsistencia en las situaciones posteriores a desastres y conflictos, proporcionando, por ejemplo, oportunidades de empleo temporal y permanente y formación profesional. Finalmente, el informe subraya que "las personas con discapacidad deben participar activamente en la reactivación de la comunidad, pues su exclusión afecta a su propia vida y a la de toda la comunidad" (OACNUDH, 2015).

Siempre respecto al contenido del artículo 11 de la Convención, y desde el punto de vista de sus implicaciones prácticas, la International Disability Alliance propone, en su documento orientativo sobre la aplicación eficaz de los mecanismos internacionales de vigilancia de los derechos humanos para la protección de los derechos de las personas con discapacidad, plantear las siguientes preguntas: si su Estado se enfrenta actualmente a una situación derivada de una emergencia humanitaria, ¿se están protegiendo adecuadamente los derechos de las personas con discapacidad que sufren esta situación (refugiados, personas desplazadas internamente) tanto en los campos de refugiados como en los asentamientos urbanos?; si su Estado proporciona ayuda por emergencias humanitarias a otros Estados, ¿se presta la ayuda de forma que beneficie por igual a las personas con discapacidad y a las demás personas, garantizándose un ajuste razonable y la accesibilidad a todos los servicios e instalaciones?; ¿los protocolos de emergencia contemplan medidas que garantizan que las personas con discapacidad no sean discriminadas o excluidas en caso de que se produzca una emergencia humanitaria? (IDA, 2010, p. 40).

Por supuesto, el artículo 11 interactúa necesariamente y debe entenderse en conexión estrecha con el resto del articulado de la Convención. En primer lugar, con el artículo 9, sobre accesibilidad, que establece que los 
Estados Parte deberán adoptar (en todo momento) las medidas pertinentes para asegurar el acceso de las personas con discapacidad, en igualdad de condiciones con las demás, al entorno físico, el transporte, la información y las comunicaciones, incluidos los sistemas y las tecnologías de la información y las comunicaciones, y a otros servicios e instalaciones abiertos al público o de uso público, tanto en zonas urbanas como rurales, procediendo a identificar y eliminar los obstáculos y barreras de acceso existentes. En segundo lugar, teniendo en cuenta los elevados índices de abuso y violencia (también sexual y de género) contra las personas con discapacidad registrados en contextos de crisis (Handicap International, 2015, p. 9; ECHO, 2019, p. 7), con el artículo 16, que obliga a los Estados Parte a adoptar todas las medidas pertinentes para proteger a las personas con discapacidad, tanto en el seno del hogar como fuera de él, contra todas las formas de explotación, violencia y abuso, incluidos los aspectos relacionados con el género. Igualmente respecto a los artículos 10 y 17, sobre el derecho a la vida y a la protección de la integridad personal, el 21, relativo al acceso a la información, los artículos 24 y 25, sobre acceso a la educación y la salud, etc.

\section{La Carta sobre la Inclusión de Personas con Discapacidad en la Acción Humanitaria}

Sobre la base del artículo 11 de la CDPD, la cuestión específica de la toma en consideración de la discapacidad en el ámbito humanitario fue desarrollada posteriormente, con mayor detalle, en la Carta sobre la Inclusión de Personas con Discapacidad en la Acción Humanitaria (2016), aprobada en el marco de la Cumbre Humanitaria Mundial y suscrita por Estados, organizaciones internacionales, organizaciones de personas con discapacidad y otras organizaciones de la sociedad civil. La Carta pretende abarcar a todas las personas con discapacidad y ser de aplicación a todas las situaciones de riesgo y emergencias humanitarias, y a todas las fases de una respuesta humanitaria, desde las actividades de preparación para la emergencia y el inicio de las crisis hasta el proceso de transición y la posterior recuperación ${ }^{16}$.

El documento identifica cinco principios básicos para que la acción humanitaria incluya a las personas con discapacidad: no discriminación; participación; políticas inclusivas; respuesta y servicios inclusivos; cooperación y coordinación. Dentro de esas cinco líneas, recoge compromisos concretos, como el de promover la participación significativa de personas con discapacidad y sus organizaciones representativas en la evaluación de las necesidades, el diseño, la implementación, coordinación, monitoreo y evaluación de los programas de preparación y respuesta humanitaria y asegurar desde su liderazgo, sus habilidades, sus experiencias y otras capacidades su participación activa en la toma de decisiones y en los procesos de planeamiento como también la inclusión en los mecanismos de coordinación apropiados; garantizar que los servicios y la asistencia humanitaria estén disponibles en forma igualitaria y sean accesibles a toda persona con discapacidad, y garantizar la disponibilidad, asequibilidad y el acceso a servicios especializados, incluyendo tecnología de apoyo en el corto, mediano y largo plazo; trabajar para la eliminación de las barreras físicas y de comunicación, incluyendo la provisión de información sistemática en la planificación, la prepa-

16. De acuerdo con la Estrategia Internacional para la Reducción de Desastres de las Naciones Unidas, "las tareas de rehabilitación y reconstrucción dentro del proceso de recuperación comienzan inmediatamente después de que ha finalizado la fase de emergencia, y deben basarse en estrategias y políticas preexistentes que faciliten el establecimiento de responsabilidades institucionales claras y permitan la participación pública", representando "una valiosa oportunidad para desarrollar y ejecutar medidas para reducir el riesgo de desastres y aplicar el principio de "reconstruir mejor" (UNISDR, 2009, p. 26). 
ración y la respuesta, procurando asegurar la accesibilidad de los servicios mediante la incorporación de un diseño universal en la programación, las políticas y en toda reconstrucción postemergencia; sensibilizar a todo el personal humanitario a nivel nacional e internacional, a las autoridades locales y nacionales sobre los derechos, protección y seguridad de las personas con discapacidad y fortalecer aún más sus capacidades y habilidades con el fin de identificar e incluir personas con discapacidad en los mecanismos de preparación y respuesta humanitarias; o promover la coordinación entre los actores humanitarios y de desarrollo con el fin de fortalecer los sistemas de servicio nacionales e internacionales inclusivos de personas con discapacidad y capitalizar las oportunidades de reconstruir más ciudades y comunidades inclusivas.

Tras la adopción de la Carta, las principales barreras y desafíos que aún existen para los avances en materia de inclusión de la discapacidad en la acción humanitaria, identificadas por las organizaciones de la sociedad civil, han sido: el bajo nivel de comprensión y conocimiento y de prioridad dada en la respuesta a las necesidades de las personas con discapacidad; la falta de datos desagregados, y la falta de financiación. Respecto a la primera de dichas cuestiones, prevalece la falta de comprensión de los distintos factores que interaccionan y que afectan la protección de las personas, con el resultado de que las personas con discapacidad no tienen prioridad en la acción humanitaria, así como la realidad de que los agentes humanitarios todavía están lejos de incorporar sistemáticamente enfoques inclusivos en sus programas, existiendo aún una gran necesidad de sensibilización y de creación de capacidades para el personal humanitario dentro de los programas sobre el terreno (Handicap International, 2017).

Uno de los resultados de la adopción de la Carta fue el desarrollo de las Directrices sobre la inclusión de personas con discapacidad en la acción humanitaria por parte del Inter-Agency Standing Committee (IASC) ${ }^{17}$, publicadas en 2019 y consideradas como las primeras directrices humanitarias desarrolladas con y por personas con discapacidad y sus organizaciones representativas en asociación con los actores humanitarios tradicionales. Las acciones recomendadas en cada capítulo de las directrices colocan a las personas con discapacidad en el centro de la acción humanitaria, tanto en calidad de actores como de miembros de las poblaciones o comunidades afectadas. Son específicas para las personas con discapacidad y para el contexto de la acción humanitaria, y aunque se basan en normas y directrices existentes y más generales, están diseñadas para promover la implementación de programas humanitarios de calidad en diferentes contextos.

\section{Otros documentos, informes, marcos estratégicos y guías operativas de interés acerca de las personas con discapacidad en el ámbito humanitario}

En la Cumbre Global sobre Discapacidad de 2018, celebrada en Londres, los gobiernos, organismos multilaterales y organizaciones no gubernamentales participantes ${ }^{18}$ aprobaron el documento Charter for Change, de cuyos 10 puntos u objetivos, uno estaba dedicado íntegramente al ámbito humanitario: "Cambiar las prácticas existentes para que toda la acción humanitaria sea totalmente inclusiva y accesible para las personas

17. El IASC es un foro interinstitucional para la coordinación, el desarrollo de políticas y la toma de decisiones que involucra a los socios humanitarios clave, tanto en el marco de la ONU como de fuera del sistema de Naciones Unidas. El IASC se estableció en junio de 1992 en respuesta a la Resolución 46/182 de la Asamblea General sobre el fortalecimiento de la asistencia humanitaria.

18. https://bit.ly/3wuFGut. 
con discapacidad. Integraremos la inclusión en todos los sectores humanitarios y de reducción del riesgo de desastres, e implementaremos los compromisos asumidos en la Carta sobre la Inclusión de Personas con Discapacidad en la Acción Humanitaria". Además, adoptaron más de 81 compromisos ${ }^{19}$ orientados específicamente a fortalecer aún más la inclusión de las personas con discapacidad en la acción humanitariaª.

A partir de ahí, algunas agencias de desarrollo estatales (AECID, 2018; GIZ, 2019), entidades de personas con discapacidad y organizaciones de la sociedad civil (Handicap International/CBM International/IDA, 2019) han venido también produciendo guías, orientaciones y documentos de buenas prácticas. Otros documentos de interés sobre cómo trasladar todas estas cuestiones a los distintos ámbitos de la actuación humanitaria podrían ser las Guidance on strengthening disability inclusion in Humanitarian Response Plans, elaboradas por las Naciones Unidas con el apoyo de la cooperación británica y la participación de la ONG Humanity \& Inclusion (DFID, 2017); los Humanitarian inclusion standards for older people and people with disabilities (Age and Disability Consortium, 2018); o las orientaciones sobre normas para la inclusión, protección y atención de personas con discapacidad en emergencias y desastres (UNICEF/CEPREDENAC, 2019) y los manuales para la inclusión de niños y niñas con discapacidad en la acción humanitaria publicadas por UNICEF en colaboración con la ONG Handicap International ${ }^{21}$. En ese sentido, es importante recordar que los niños, niñas y adolescentes con discapacidad deben tener acceso a servicios médicos, jurídicos, psicológicos, sociales, educativos y de otro tipo dedicados a las víctimas de violencia sexual, y que la educación tiene una importante función de apoyo a los niños, niñas y adolescentes con discapacidad cuando pasan a la etapa de recuperación posterior a conflictos o desastres (OACNUDH, 2015).

El Marco de Sendai para la Reducción del Riesgo de Desastres, al que ya nos hemos referido anteriormente, también se destaca por haber integrado de forma clara la toma en consideración de la discapacidad, y exige que todas las políticas de reducción del riesgo de desastres integren dicha perspectiva, además de una toma de decisiones inclusiva, fundamentada en la determinación de los riesgos y basada en la divulgación de datos desglosados, entre otras cosas, por discapacidad (ONU, 2015). Además, en 2015 se adoptó la Declaración de Dhaka sobre Discapacidad y Gestión de Riesgos de Desastres ${ }^{22}$, haciendo hincapié en el empoderamiento de las personas con discapacidad y su inclusión efectiva, y en apoyar iniciativas de gestión del riesgo de desastres, análisis de riesgo y bancos de datos inclusivos basados en las comunidades que contribuyan a los sistemas de alerta temprana ${ }^{23}$ a nivel local, nacional y regional y a la adopción de planes de preparación para desastres que sean accesibles para todas las personas. Es evidente que existe una clara necesidad de colaboración, de manera general, entre actores humanitarios y especialistas en reducción del riesgo de desastres para abordar las vulnerabilidades subyacentes y sentar las bases para el desarrollo sostenible. Esta necesidad de fortalecer dicho nexo se extiende también a la inclusión efectiva de las personas con discapacidad y sus necesidades. Sin embargo, en el presente artículo no profundizaremos en este aspecto, y nos atendremos al ámbito tradicional de la actuación humanitaria ${ }^{24}$.

19. https://bit.ly/3f8zeDy.

20. Pueden consultarse aquí: https://bit.ly/3ys|4U8.

21. Se trata de seis manuales sobre la inclusión de niños, niñas y adolescentes con discapacidad en los programas humanitarios (UNICEF, 2017a), con especial énfasis en la protección de la infancia (UNICEF, 2017b), incluyendo, entre otros materiales, guías específicas para los ámbitos de la nutrición (UNICEF, 2018), la salud (UNICEF, 2017d), la educación (UNICEF, 2017c) o la higiene y el derecho al agua y al saneamiento (UNICEF, 2017e).

22. https://bit.ly/2RtxgVn.

23. Entendidos como el "conjunto de capacidades necesarias para generar y difundir información de alerta que sea oportuna y significativa, con el fin de permitir que las personas, las comunidades y las organizaciones amenazadas por una amenaza se preparen y actúen de forma apropiada y con suficiente tiempo de anticipación para reducir la posibilidad de que se produzcan pérdidas o daños" (UNISDR, 2009, p. 33).

24. Sin embargo, el Consenso Europeo sobre la Ayuda Humanitaria considera que las medidas destinadas a reducir el riesgo de catástrofes, "incluida la preparación ante las catástrofes y la recuperación tras las mismas", no solo "resultan esenciales para salvar vidas y permitir que las comunidades 
En 2019 la ONU lanzó su Estrategia de Inclusión de la Discapacidad, elaborada con la intención de dotar a la organización con un marco estratégico omnicomprensivo que permitiera asegurar la plena inclusión de la discapacidad en todos los niveles de trabajo del sistema de Naciones Unidas, tanto a nivel interno (reforzando la accesibilidad en todo el sistema para las personas con discapacidad y la integración de sus derechos) como de manera transversal en los pilares humanitario, de desarrollo y de paz y seguridad, desde un enfoque de derechos humanos. La Estrategia incluye una política común para todos los departamentos, agencias, fondos y programas del sistema, así como un marco conjunto de rendición de cuentas con 15 indicadores que se centra en cuatro esferas: el liderazgo, la planificación estratégica y la gestión; la inclusividad; la programación; y la cultura institucional. Además, la Estrategia prevé un sistema de calificación para que los equipos de las Naciones Unidas sobre el terreno rindan también cuentas de su desempeño respecto de la inclusión de la discapacidad (ONU, 2019).

El primer Informe del Secretario General sobre la aplicación de la Estrategia, tras insistir en la necesidad imperiosa de mantener consultas estrechas con las personas con discapacidad y las alianzas con las organizaciones que las representan por su carácter esencial para la inclusión efectiva de la discapacidad, puso de manifiesto que, si bien la mayoría de las entidades celebraron durante 2019 este tipo de consultas, esas consultas no se realizaron de manera sistemática, inclusiva o accesible, y que el $69 \%$ de las entidades del sistema no cumplen todavía los requisitos previstos en este indicador, mientras que por el momento solo el $20 \%$ se acerca a ellos y el $11 \%$ los cumple o los supera. Asimismo, el informe señaló que, en 2019, siete entidades que trabajan en el ámbito de la acción humanitaria colaboraron para garantizar la inclusión de las personas con discapacidad en los planes de respuesta humanitaria (ONU, 2020).

En 2020, la Relatora Especial sobre los derechos humanos de los desplazados internos presento al Consejo de Derechos Humanos un informe sobre las personas con discapacidad en el contexto del desplazamiento interno ${ }^{25}$. En él recordaba que, a tenor de lo dispuesto en el artículo 11 de la CDPD, los Estados partes están específicamente obligados a adoptar todas las medidas necesarias para garantizar la protección y la seguridad de las personas con discapacidad en las situaciones de conflicto armado y desastres, subrayaba que todas las disposiciones de la Convención siguen siendo pertinentes en las situaciones de desplazamiento e insistía en que los Estados y otros agentes humanitarios deben incorporar sistemáticamente la discapacidad en sus políticas y marcos de protección a fin de asegurar que no se desatienda la seguridad de las personas con discapacidad durante los desplazamientos.

El informe concluía que, si bien en el último decenio se han registrado progresos considerables en el reconocimiento de los derechos de las personas con discapacidad en los entornos humanitarios y de desarrollo, los Estados y otros agentes humanitarios deben pasar de la concienciación sobre la discapacidad a una estrategia proactiva de inclusión de la discapacidad basada en los derechos humanos en la gestión de los desplazamientos internos. Entre sus recomendaciones, la relatora señaló la necesidad de que los Estados y todos los agentes humanitarios pertinentes velen por que todos sus servicios, programas y actividades destinados a prevenir los desplazamientos forzosos y a proteger y ayudar a los desplazados internos sean accesibles para las personas con discapacidad, sin discriminación alguna, determinando y eliminando las barreras relacionadas con la actitud, el entorno y las comunicaciones, y realizando ajustes razonables cuando sea necesario. La relatora incluso proponía que los donantes que financian el apoyo nacional e

incrementen su capacidad de hacer frente a las emergencias", sino también que "las actividades de desarrollo de capacidades para prevenir y atenuar las consecuencias de las catástrofes y mejorar la respuesta humanitaria forman parte también de la ayuda humanitaria" (Unión Europea, 2008). 25. $\mathrm{A} / \mathrm{HRC} / 44 / 41$ 
internacional a los desplazados internos deberían hacer que la inclusión de la discapacidad fuera un requisito de las propuestas de proyectos. Pero la cuestión de los desplazados internos desborda el estricto ámbito humanitario (OCHA, 2017; OCHA, 2019b), y requiere necesariamente del concurso de los actores y las políticas de desarrollo y un fuerte énfasis en el nexo. La Agenda para la Humanidad surgida en 2016 de la Cumbre Humanitaria Mundial enmarcó el desplazamiento forzado como una cuestión de desarrollo si se pretende abordar el desplazamiento interno desde un compromiso a largo plazo para la obtención de soluciones duraderas y sostenibles (Asfour et al., 2020).

\section{Conclusiones}

Las investigaciones han demostrado que en las operaciones humanitarias sobre el terreno a menudo falta capacidad de apoyo a las personas con discapacidad en situaciones de riesgo y emergencia humanitaria, a pesar de que dichas situaciones de riesgo pueden hacer que las personas con discapacidad sean "más vulnerables a la violencia, el descuido, el maltrato físico o la explotación sexual, al tiempo que se debilita el cumplimiento de la ley y se fragilizan los mecanismos de seguridad y apoyo" (OACNUDH, 2015). Las personas con discapacidad a menudo se enfrentan a riesgos agudizados en situaciones de crisis económica y de trastornos políticos, y a la vez, a menudo tienen también menos probabilidades que el resto de personas de beneficiarse de las intervenciones o la asistencia humanitaria implementada en respuesta a estas crisis (Groce et al., 2011a). No solo eso, sino que las personas con discapacidad corren un riesgo especial de marginación y discriminación como resultado de las políticas y prácticas de exclusión de las comunidades y agencias humanitarias (IFRC, 2007, pp. 87-91).

Tanto la CDPD como la Clasificación Internacional del Funcionamiento, de la Discapacidad y de la Salud subrayan el papel que desempeña el entorno para facilitar o restringir la participación de las personas con discapacidad (los llamados obstáculos discapacitantes). El Informe Mundial sobre la Discapacidad señaló como principales obstáculos los siguientes: políticas y normas insuficientes; actitudes negativas (creencias y prejuicios que dificultan o impiden el acceso a la educación, al empleo, a la atención sanitaria y la participación social); los problemas con la prestación de servicios, incluida la prestación insuficiente de los mismos; la falta de accesibilidad (en edificios, incluidos los lugares públicos, y sistemas de transporte, pero también en cuanto a la información); la falta de consulta y participación; la falta de datos rigurosos y comparables sobre la discapacidad y de pruebas objetivas sobre los programas que funcionan (que dificultan la comprensión y el análisis e impiden que se adopten medidas efectivas) (OMS, 2011). Este es el panorama que preexiste, en la mayoría de casos, a la situación de desastre que dará pie a la actuación humanitaria, y es por tanto también el contexto que tendrán que tener siempre en cuenta los actores humanitarios a la hora de diseñar sus intervenciones y de llevarlas a cabo, con el fin de garantizar que la ayuda llegue realmente a quien más la necesita.

Por todo ello, los programas de respuesta y preparación deben considerar las capacidades y necesidades de todas las personas con discapacidad y realizar esfuerzos deliberados para eliminar las barreras físicas, de comunicación y de actitud para su acceso y participación, sin olvidar que los riesgos para las mujeres y niñas con discapacidad pueden verse agravados por la desigualdad y la discriminación de género (Sphere Association, 2018, p. 14). Para hacer efectivos los compromisos de preparación y respuesta inclusivas para situaciones 
de emergencia es preciso contar con recursos suficientes, oportunos y previsibles. Es fundamental que los donantes inviertan en actividades humanitarias que incluyan a las personas con discapacidad.

Los Estados, los agentes no estatales y los actores humanitarios deben igualmente fomentar la capacidad de las partes interesadas, tanto militares como civiles, el personal de mantenimiento de la paz y otros trabajadores sobre el terreno que intervengan en situaciones de emergencia, en relación con los derechos de las personas con discapacidad (OACNUDH, 2015). Sobre el ámbito de la reconstrucción postconflicto y la construcción de paz, ha habido críticas a la falta de toma en consideración de las mujeres con discapacidad en el marco de la agenda de mujeres, paz y seguridad, llegando a afirmarse que, a pesar de los progresos logrados a partir de la Resolución 1325 para dar a las mujeres "un lugar en la mesa en la consolidación de la paz y la reconciliación, las mujeres con discapacidad están desaparecidas y son ignoradas y no han tenido un papel en estos procesos" (Ortoleva, 2012).

Durante años, las organizaciones humanitarias y las entidades de la sociedad civil habían venido insistiendo en la necesidad de avanzar en cuestiones concretas en el ámbito humanitario, incluyendo cuestiones relativas a las personas desplazadas y refugiadas - lograr que todas las instalaciones (incluidos campamentos y refugios), servicios e información relevante sean accesibles para las personas con discapacidad, incluyendo la selección de la ubicación, planificación y diseño de infraestructura y servicios de los campamentos; promover la inclusión de personas con todo tipo de discapacidad en los procesos comunitarios de toma de decisiones en los campamentos y en todas las etapas del ciclo del programa; promover el acceso pleno e igualitario a los servicios principales (agua y saneamiento, alimentación y nutrición, distribuciones no alimentarias, salud y servicios de salud mental, educación, formación profesional y de habilidades y educación de adultos, generación de ingresos y empleo, oportunidades y programas psicosociales), así como proporcionar servicios específicos cuando fuere necesario (servicios de salud especializados, educación para necesidades especiales), etc. (Women's Refugee Commission, 2008) - . La adopción de la CDPD -con la consiguiente consagración de un "nuevo paradigma en el modo de pensar y tratar jurídicamente la discapacidad: el modelo de los derechos, articulado en torno a la autonomía, la no discriminación, la igualdad de oportunidades, el reconocimiento de la diversidad, la participación y la inclusión" (Seoane, 2010) - y la aprobación de la Carta sobre la Inclusión de Personas con Discapacidad en la Acción Humanitaria marcan un hito significativo en cuanto al marco con el que cuenta la comunidad humanitaria internacional para abordar estas cuestiones, desde una apuesta clara y sistemática por un enfoque de derechos.

La CDPD empieza recordando que, "para lograr la plena protección de las personas con discapacidad, en particular durante los conflictos armados y la ocupación extranjera, es indispensable que se den condiciones de paz y seguridad basadas en el pleno respeto de los propósitos y principios de la Carta de las Naciones Unidas y se respeten los instrumentos vigentes en materia de derechos humanos" (ONU, 2006). Los Estados no solo deben abstenerse de causar daño (do no harm) en sus actividades de cooperación internacional (incluida la ayuda humanitaria) mediante la promoción de prácticas contrarias a la CDPD, sino que deben, en cambio, aplicar de manera proactiva un modelo basado en los derechos humanos en el ciclo de gestión de emergencias (OACNUDH, 2015).

Además de las normas en materia de derechos humanos, mientras dure el conflicto será de aplicación igualmente el derecho internacional humanitario. Debe siempre tenerse presente que el derecho internacional humanitario y el derecho internacional de los derechos humanos son complementarios y se refuerzan mutuamente en lo que respecta a la protección de los derechos de las personas con discapacidad en situaciones de riesgo y emergencia humanitaria (Iguyovwe, 2008). En ese sentido, por ejemplo, el citado estudio te- 
mático sobre los derechos de las personas con discapacidad en virtud del artículo 11 de la CDPD subrayaba que "las normas que exigen una prohibición total de la privación de libertad por motivo de discapacidad y la detención no consentida en los centros de salud mental y otras instituciones, y la obligación de realizar ajustes razonables para las personas con discapacidad privadas de libertad deben guiar la interpretación y la aplicación del derecho internacional humanitario" (OACNUDH, 2015).

Se ha insistido ya abundantemente en la importancia (la necesidad) de incorporar a las organizaciones de las personas con discapacidad en las respuestas humanitarias (Buscher, 2018). Estas deben ser incluidas en todas las fases de la actuación, es decir, tanto en los planes de preparación y en la respuesta como en los planes de recuperación o reconstrucción. Para facilitar la integración en las áreas de las emergencias y desastres, el tema de la discapacidad debería ser considerado de manera sistemática e integrarse tanto en la evaluación de riesgos y las medidas para reducir vulnerabilidad y evitar riesgos como en las medidas de la respuesta adaptativa, la recuperación/reconstrucción efectiva y la rehabilitación, tanto en los niveles locales y regionales como estatales.

Sin embargo, "en su mayoría, los planes de preparación y respuesta ante los eventos de emergencias y desastres no incluyen las necesidades de las personas con discapacidad y mucho menos a ellas mismas en las actividades de gestión de los planes", y ello a pesar de que la inclusión de dichas necesidades en todas las etapas del proceso de gestión de los desastres, y especialmente durante las etapas de planificación y preparación, puede contribuir a reducir de forma significativa la vulnerabilidad de estas personas y aumentar la eficacia de los esfuerzos gubernamentales de respuesta y recuperación" (Vásquez, 2013). Respecto a cómo asegurar en concreto la inclusión de la discapacidad en la planificación, la Unión Europea, en su guía de orientaciones operativas, identifica dos pasos esenciales: un análisis del riesgo mediante la identificación de barreras y facilitadores, y un abordaje de los riesgos mediante la incorporación de un enfoque de protección (ECHO, 2019).

En definitiva: tras la adopción de la CDPD, y especialmente durante los últimos cinco años, se han producido numerosos avances que han contribuido a establecer y consolidar un marco conceptual, estratégico y de actuación a nivel global en el ámbito humanitario desde un enfoque inclusivo que tenga debidamente en cuenta las necesidades de las personas con discapacidad. Sin embargo, los informes de seguimiento y análisis realizados por la sociedad civil ponen de relieve las brechas que todavía siguen existiendo para que esos principios y consensos teóricos y normativos se pongan realmente en práctica por parte de los Estados y organismos internacionales responsables, se respeten por parte de las partes en conflicto y se operativicen por parte del conjunto de los actores humanitarios. La Agenda 2030 para el Desarrollo Sostenible ha supuesto un espaldarazo adicional a la centralidad de la inclusión de la diversidad, la no discriminación y el respecto de los derechos humanos para no dejar a nadie atrás (CERMI, 2019), especialmente a aquellas personas que más lo necesitan cuando más lo necesitan. Pero aún queda mucho trabajo para llevar todas estas obligaciones y recomendaciones a la práctica, y garantizar así una acción humanitaria que logre no dejar de lado a las personas con discapacidad. 


\section{Referencias bibliográficas}

Abellán, A. e Hidalgo, R. M. (2011). Definiciones de discapacidad en España. Informes Portal Mayores, 109. https:// bit.ly/3oEzb5e.

AECID (2018). Guía para la inclusión de la discapacidad en cooperación para el desarrollo. Estado de situación en la AECID y orientaciones. Agencia Española de Cooperación Internacional para el Desarrollo.

Age and Disability Consortium (2018). Humanitarian inclusion standards for older people and people with disabilities. CBM International/HelpAge International/Handicap International.

Asfour, H. et al. (2020). Internal Displacement as a Development Challenge. Internal Displacement Research Programme https://bit.ly/3uaBGxk.

de Asís, R. (2013). Sobre el modelo social de la discapacidad: críticas y éxitos. El tiempo de los derechos, 1. https://bit.ly/3hG9U9D.

Banks, L. M. et al. (2019). Are current approaches for measuring access to clean water and sanitation inclusive of people with disabilities? Comparison of individual- and household-level access between people with and without disabilities in the Tanahun district of Nepal. PloS One, 14(10).

Biel, I. y Bolaños, T. G. (2018a). Persons with disabilities and the Colombian armed conflict. Disability \& Society, 33(3), pp. 487-491.

Biel, I. y Bolaños, T. G. (2018b). Are persons with disabilities included in the Colombian peace process? Disability \& Society, 33(4), pp. 638-643.

Briscoe, I. (2013). Non-conventional armed violence and non-state actors: challenges for mediation and humanitarian action. Norwegian Peacebuilding Resource Centre.

Buscher, D. (2018). Engaging Organizations of Persons with Disabilities in Humanitarian Responses. Societies, $8(4)$.

Cardona, J. (2007). La Organización de las Naciones Unidas y las personas con discapacidad. En C. Fernández Liesa (Dir.), La protección internacional de las personas con discapacidad. Tirant lo Blanc.

Celorio, G. y López de Munain, A. (Coords.) (2007). Diccionario de educación para el desarrollo. Instituto de Estudios sobre Desarrollo y Cooperación Internacional (UPV).

CERMI (2019). Objetivos de Desarrollo Sostenible y promoción de los derechos de las personas con discapacidad. Cinca. https://bit.ly/34bGgkl.

Consejo Noruego para los Refugiados - Handicap International (2016). Retos para la Acción Humanitaria basadas en Principios: Perspectivas desde cuatro países. Consejo Noruego para los Refugiados y Handicap International.

Davey, E. et al. (2013). A history of the humanitarian system. Western origins and foundations. Humanitarian Policy Group - Overseas Development Institute.

Degener, T. (2017). 10 years of Convention on the Rights of Persons with Disabilities. Netherlands Quarterly of Human Rights, 35(3), pp. 152-157. 
DFID (2017): Guidance on strengthening disability inclusion in Humanitarian Response Plans. UK aid. https://bit. ly/3bKTPvw.

ECHO (2019). La inclusión de las personas con discapacidad en las operaciones de ayuda humanitaria financiadas por la UE. Guía de orientaciones operativas. Unión Europea.

Egea García, C. y Sarabia Sánchez, A. (2003). La CIF: Nuevos conceptos y términos de la discapacidad de la OMS. Servicios Sociales y Política Social 62, pp. 9-14.

Egea, C. y Sarabia, A. (2004). Visión y modelos conceptuales de la discapacidad. Polibea, 73, pp. 29-42.

Eide, A. H. e Ingstad, B. (2011). Some concluding thoughts: the way ahead. En A. H. Eide y B. Ingstad (Eds.), Disability and poverty. A global challenge (pp. 225-232). Policy Press.

El Orden Mundial (4 de septiembre de 2020). ¿Qué es la acción humanitaria? https://bit.ly/3bLSioV.

Fox, F. (2001). New Humanitarianism: Does It Provide a Moral Banner for the 21st Century?. Disasters, 25, pp. 275-289.

GIZ (2019). Disability Inclusion Matters: Inclusion of persons with disabilities in the context of forced displacement. https://gladnetwork.net/sites/default/files/2019-09/giz_forced_displacement.pdf.

Glasman, J. (2020). The invention of impartiality: the history of a humanitarian principle, from a legal, strategic and algorithmic perspective. Humanitarian Alternatives, 15, pp. 8-21.

González Martín, N. (2008). Convención de Naciones Unidas sobre los Derechos de las Personas con Discapacidad. Anuario Mexicano de Derecho Internacional, 8, pp. 527-540.

Gordon, S. y Donini, A. (2016). Romancing principles and human rights: are humanitarian principles salvageable? International Review of the Red Cross, 97(897/898), pp. 77-109.

Groce, N. et al. (2011a). Disability and Poverty: the need for a more nuanced understanding of implications for development policy and practice. Third World Quarterly, 32(8), pp. 1493-1513.

Groce, N., et al. (2011b). Water and sanitation issues for persons with disabilities in low- and middle-income countries: a literature review and discussion of implications for global health and international development. Journal of Water and Health, 9(4), pp. 617-627.

Haider, H. (2013). International legal frameworks for humanitarian action: Topic guide. GSDRC, University of Birmingham.

Handicap International/CBM International/IDA (2020). Article 11 of the Convention on the Rights of Persons with Disabilities (CRPD): legal frameworks guiding inclusive humanitarian action and guidance for CRPD reporting. Handicap International. https://bit.ly/3fBUFvB .

Handicap International/CBM International/IDA (2019). Inclusion of persons with disabilities in humanitarian action. Case studies. https://interagencystandingcommittee.org/system/files/2020-11/IASC\%20Guidelines $\% 20$ on $\% 20$ the $\% 20$ Inclusion\%20of\%20Persons \%20with\%20Disabilities \%20in\%20Humanitarian $\% 20$ Action\%2C\%202019_0.pdf.

Handicap International (2017). Charter on Inclusion of Persons with Disabilities in Humanitarian Action. Update on Progress since the World Humanitarian Summit. Handicap International. https://bit.ly/3oEcfDx.

Handicap International (2015). Disability in humanitarian contexts. Handicap International. 
Harpur, P. (2012). Embracing the new disability rights paradigm: the importance of the Convention on the Rights of Persons with Disabilities. Disability \& Society, 27(1), pp. 1-14.

Hashemi, G., et al. (2020). Barriers to accessing primary healthcare services for people with disabilities in low and middle-income countries: a meta-synthesis of qualitative studies. Disability and Rehabilitation.

Hemingway, L. y Priestly, M. (2006). Natural hazards, human vulnerability and disabling societies: A disaster for disabled people? The Review of Disability Studies: An International Journal, 2(3), pp. 57-67.

Henckaerts, J. M. (2005). Study on customary international humanitarian law: A contribution to the understanding and respect for the rule of law in armed conflict. International Review of the Red Cross, 87(857), pp. 175-212.

Hernández Ríos, M. I. (2015). El concepto de discapacidad: de la enfermedad al enfoque de derechos. Revista CES Derecho, 6(2), pp. 46-59.

Hilhorst, D. (2018). Classical humanitarianism and resilience humanitarianism: making sense of two brands of humanitarian action. Journal of International Humanitarian Action, 3(15).

IASC (2019). Guidelines on Inclusion of Persons with Disabilities in Humanitarian Action. IASC. https://bit. ly/3wq504w.

IDA (2010). Aplicación eficaz de los mecanismos internacionales de vigilancia de los derechos humanos para la protección de los derechos de las personas con discapacidad. International Disability Alliance.

IFRC (2007). World Disasters Report 2007. International Federation of Red Cross and Red Crescent Societies.

Iguyovwe, R. (2008). The Inter-play between International Humanitarian Law and International Human Rights Law. Commonwealth Law Bulletin, 34(4), pp. 749-789.

Jette, A. M. (2009). Toward a common language of disablement. The Journals of Gerontology Series A: Biological Sciences and Medical Sciences, 64(11), pp. 1165-68.

Kett, M. (2010). Disability and poverty in post-conflict countries. En T. Barron y J. M Ncube (Eds.), Poverty and disability. Leonard Cheshire Disability.

López Bastías, J. L. (2019). La conceptualización de la discapacidad a través de la historia: una mirada a través de la evolución normativa. Revista de la Facultad de Derecho de México, LXIX(273), pp. 835-855.

Mačák, K. (2016). A matter of principle(s): The legal effect of impartiality and neutrality on States as humanitarian actors. International Review of the Red Cross, 97(897/898), pp. 157-181.

Mackintosh, K. (2000). The principles of humanitarian action in international humanitarian law. Overseas Development Institute.

McDonald, K. E. y Raymaker, D. M. (2013). Paradigm Shifts in Disability and Health: Toward More Ethical Public Health Research. American Journal of Public Health, 103(12), pp. 2165-2173.

McFarland, S. (2017). A Brief History of An Unsung Hero and Leader - Jean Henry Dunant and the Founding of the Red Cross at the Geneva Convention. International Journal of Leadership and Change, 5(1-5), pp. 41-46.

Meininghaus, E. (2016). Humanitarianism in intra-state conflict: aid inequality and local governance in governmentand opposition-controlled areas in the Syrian war. Third World Quarterly, 37(8), pp. 1454-1482.

Mercer, J. R. (1992). The Impact of Changing Paradigms of Disability on Mental Retardation in the Year 2000. En L. Rowitz (Ed.), Mental Retardation in the Year 2000. Disorders of Human Learning, Behavior, and Communication (pp. 15-38). Springer. 
Mitchell, D. y Karr, V. (Eds.). (2014). Crises, conflict and disability: Ensuring equality. Routledge.

Mittler, P. (2015). The UN Convention on the Rights of Persons with Disabilities: Implementing a Paradigm Shift. Journal of Policy and Practice in Intellectual Disabilities, 12(2), pp. 79-89.

National Council on Disability (2002): A White Paper: Understanding the Role of an International Convention on the Human Rights of People with Disabilities. National Council on Disability https://bit.ly/3fG0IQ1.

OACNUDH (2014). Convención sobre los derechos de las personas con discapacidad. Guía de formación. Oficina del Alto Comisionado de las Naciones Unidas para los Derechos Humanos.

OACNUDH (2015). Estudio temático sobre los derechos de las personas con discapacidad en virtud del artículo 11 de la Convención sobre los Derechos de las Personas con Discapacidad, relativo a las situaciones de riesgo y emergencias humanitarias. Informe al Consejo de Derechos Humanos. Oficina del Alto Comisionado de las Naciones Unidas para los Derechos Humanos.

OCHA (2017). Breaking the Impasse: Reducing Protracted Internal Displacement as a Collective Outcome. United Nations Office for the Coordination of Humanitarian.

OCHA (2019a). Guía para gobiernos. Acción humanitaria internacional. Oficina de Coordinación de Asuntos Humanitarios de las Naciones Unidas.

OCHA (2019b). Reducing Protracted Internal Displacement: A Snapshot of Successful Humanitarian-Development Initiatives. United Nations Office for the Coordination of Humanitarian Affairs.

OMS (1980). Clasificación Internacional de Deficiencias, Discapacidades y Minusvalías. Ministerio de Asuntos Sociales. Instituto Nacional de Servicios Sociales.

OMS (2001). Clasificación Internacional del Funcionamiento, de la Discapacidad y de la Salud. Madrid: Organización Mundial de la Salud y Ministerio de Trabajo y Asuntos Sociales-Secretaría de Estado de Servicios Sociales, Familias y Discapacidad. Instituto de Mayores y Servicios Sociales.

OMS (2011). Informe mundial sobre la discapacidad. Organización Mundial de la Salud.

OMS (2013). Guidance Note on Disability and Emergency Risk Management for Health. World Health Organization.

ONU (2006). Convención sobre los Derechos de las Personas con Discapacidad. ONU. https://bit.ly/3yußekG.

ONU (2015). Marco de Sendai para la Reducción del Riesgo de Desastres 2015-2030. ONU. https://bit.ly/2RAenji.

ONU (2019). Estrategia de las Naciones Unidas para la Inclusión de la Discapacidad. ONU. https://bit.ly/2SgwhaM.

ONU (2020). Informe del Secretario General sobre la aplicación de la Estrategia de las Naciones Unidas para la Inclusión de la Discapacidad. ONU. https://bit.ly/3u6Vr9i.

Ortoleva, S. (2012). Who's missing? Women With Disabilities In U.N. Security Council Resolution 1325 National Action Plans. ILSA Journal of International \& Comparative Law, 18(2).

Palacios, A. (2017). El modelo social de discapacidad y su concepción como cuestión de derechos humanos. Revista Colombiana de Ciencias Sociales, 8(1), pp. 14-18.

Parra-Dussan, C. (2010). Convención sobre los Derechos de las Personas con Discapacidad: antecedentes y sus nuevos enfoques. International Law: Revista Colombiana de Derecho Internacional, 16, pp. 347 - 380.

Pérez de Armiño, K. (Dir.) (2008). Diccionario de acción humanitaria y cooperación al desarrollo. Icaria - HEGOA.

Pictet, J. (1979). The Fundamental Principles of the Red Cross: Commentary. Henry Dunant Institute. 
PNUD (2016). A Principled Approach to Conflict Sensitive Do No Harm Programming in the context of Federal Iraq and the Kurdistan Region. PNUD. https://bit.ly/3u4aQqF.

Pothiawala, S. (2015). Food and Shelter Standards in Humanitarian Action. Turkish Journal of Emergency Medicine, 15(1), pp. 34-39.

Puig de la Bellacasa, R. (1990). Concepciones, paradigmas y evolución de las mentalidades sobre la discapacidad. En VV.AA. (Ed.), Discapacidad e información (pp. 63-96). Real Patronato de Prevención y Atención a Personas con Minusvalía.

Quack, M. (2018). Impartiality in discussion. En M. Quack (Ed.), Based on need alone? Impartiality in humanitarian action (pp. 10-16). Caritas Germany-Diakonie Katastrophenhilfe-MSF.

Rohwerder, B. (2013). Intellectual disabilities, violent conflict and humanitarian assistance: Advocacy of the forgotten. Disability \& Society, 28(6), pp. 770-783.

Salmón, E. (2014). El Comité de los Derechos de las Personas con Discapacidad o la institucionalidad del Derecho Internacional de los Derechos Humanos al servicio de las personas con discapacidad. En E. Salmón y R. Bregaglio (Eds.), Nueve conceptos claves para entender la Convención sobre los derechos de las personas con discapacidad (pp. 193-238). Instituto de Democracia y Derechos Humanos. Pontificia Universidad Católica del Perú.

Sanjosé, A. (2007). El primer tratado de derechos humanos del siglo XXI: la Convención sobre los derechos de las personas con discapacidad. Revista Electrónica de Estudios Internacionales, 13.

Seoane, J. A. (2010). La Convención de la ONU sobre los derechos de las personas con discapacidad: perspectiva jurídica. Siglo Cero. Revista Española sobre Discapacidad Intelectual, 42/1(237), pp. 21-32.

Smith, F. et al. (2012). Disability and disasters: The importance of an inclusive approach to vulnerability and social capital. The World We Want. UNDG. https://bit.ly/3v9LGIG.

Sphere Association (2018). The Sphere Handbook: Humanitarian Charter and Minimum Standards in Humanitarian Response. Sphere Association.

Toboso, M. y Arnau, M. S. (2008). La discapacidad dentro del enfoque de capacidad y funcionamientos de Amartya Sen. Araucaria. Revista Iberoameriana de Filosofía, Política y Humanidades, 10(20), pp. 64-94.

Townes, D. (2018). Health in Humanitarian Emergencies. Principles and Practice for Public Health and Healthcare Practitioners. Cambridge University Press.

UNESCO (2020). Global Education Monitoring Report 2020. Inclusion and education: All means all. United Nations Educational, Scientific and Cultural Organization.

UNICEF/CEPREDENAC (2019). Normas para la inclusión, protección y atención de personas con discapacidad en las emergencias y desastres. Fondo de las Naciones Unidas para la Infancia / Centro de Coordinación para la Prevención de los Desastres Naturales en América Central.

UNICEF (2017a). Inclusión de los niños y niñas con discapacidad en la acción humanitaria: Orientación general. Fondo de las Naciones Unidas para la Infancia.

UNICEF (2017b). Orientación sobre la inclusión de los niños y niñas con discapacidad en la acción humanitaria: protección de la infancia. Fondo de las Naciones Unidas para la Infancia.

UNICEF (2017c). Orientación sobre la inclusión de los niños y niñas con discapacidad en la acción humanitaria: educación. Fondo de las Naciones Unidas para la Infancia. 
UNICEF (2017d). Orientación sobre la inclusión de los niños y niñas con discapacidad en la acción humanitaria: salud y VIH/sida. Fondo de las Naciones Unidas para la Infancia.

UNICEF (2017e). Orientación sobre la inclusión de los niños y niñas con discapacidad en la acción humanitaria: agua, saneamiento e higiene (WASH). Fondo de las Naciones Unidas para la Infancia.

UNICEF (2018). Orientación sobre la inclusión de los niños y niñas con discapacidad en la acción humanitaria: nutrición. Fondo de las Naciones Unidas para la Infancia.

Unión Europea. Consenso Europeo sobre la Ayuda Humanitaria. Declaración conjunta del Consejo y los Representantes de los Gobiernos de los Estados miembros reunidos en el seno del Consejo, del Parlamento Europeo y de la Comisión Europea (2008/C 25/01). Diario Oficial de la Unión Europea, 30 de enero de 2008, C 25/1, pp. 1-12.

UNISDR (2009). Terminología sobre reducción del riesgo de desastres. ONU.

Vásquez, A. J. (2013). Las personas con discapacidad y los desastres. Desastres. Preparativos y Mitigación en las Américas, 120, p. 5.

Victoria, J. A. (2013). El modelo social de la discapacidad: una cuestión de derechos humanos. Boletín Mexicano de Derecho Comparado, 46(138), pp. 1093-1109.

Vité, S. (2009). Typology of armed conflicts in international humanitarian law: legal concepts and actual situations. International Review of the Red Cross, 91(873), pp. 69-94.

Weiss, T. G. (1998). Humanitarian Action in War Zones: Recent Experience and Future Research. En J. N. Pieterse (Eds.), World Orders in the Making (pp. 24-79). Palgrave Macmillan-Institute of Social Studies.

Women's Refugee Commission (2008). Disabilities among refugees and conflict-affected populations. Women's Refugee Commission. 